\title{
LA TOLERANCIA Y LOS FINES DE LA JUSTICIA GLOBAL EN THE LAW OF PEOPLES DE JOHN RAWLS
}

\author{
Mauricio Correa Casanova
}

En este trabajo se expone y analiza la teoría de la tolerancia desarrollada por John Rawls en el marco de los fines de la justicia global que se expresa en la elaboración del derecho de gentes. Específicamente, aquí se examinan críticamente el significado, el papel y los límites de la tolerancia según la teoría formulada por Rawls en su libro The Law of Peoples, que abarca las relaciones de las sociedades liberales con sociedades tanto liberales como no liberales. En opinión del autor, el supuesto uso analógico de la tolerancia concebido por Rawls en el proceso constructivo de la concepción de la justicia doméstica y el derecho de gentes no es plenamente satisfactorio.

Palabras clave: John Rawls; tolerancia; justicia global; liberalismo; política exterior; derecho de gentes.

Mauricio Correa. Doctor en Filosofía por la Universidad de Valencia (España). Profesor asistente adjunto de ética y filosofía social del Instituto de Filosofía de la Pontificia Universidad Católica de Chile. Miembro del Grupo Iberoamericano de Ética y Filosofía Política. Editor de Veritas, revista de filosofía y teología. Correo electrónico: maucorca@yahoo.com. 


\section{Introducción}

Como se sabe, en el complejo edificio de la teoría de la justicia diseñada por John Rawls se distinguen tres niveles de justicia: la "justicia doméstica” (domestic justice), que concierne a los principios que se aplican a la estructura básica de la sociedad; la "justicia local” (local justice), que trata de los principios que se aplican directamente a las instituciones y las asociaciones; y, finalmente, la "justicia global” (global justice), cuyos principios se aplican al derecho internacional ${ }^{1}$.

En cuanto a su modo de operación, el rasgo característico de la teoría de la justicia como equidad (justice as fairness), tal como aparece desarrollada en A Theory of Justice [1971] y Political Liberalism [1993], consiste en que prioriza y empieza con la justicia doméstica, esto es, la estructura básica de la sociedad es su objeto principal. Esto es así porque, como nos dice Rawls: "los efectos de la estructura básica sobre los objetivos, las aspiraciones y el carácter de los ciudadanos, como sobre sus oportunidades y su capacidad de sacar provecho de ellas, son efectos dominantes y presentes desde el comienzo de la vida"2. De ahí, entonces, que los principios de la justicia se apliquen primeramente a esa estructura, y aunque limitan los principios de la justicia en los otros dos ámbitos — local y global—, sin embargo no se aplican directamente ni determinan de una única manera posible los principios en las esferas local y global. Así, una vez que han sido fijados los principios de la justicia doméstica, la justicia como equidad se mueve hacia fuera, hacia la justicia global, y hacia dentro, hacia la justicia local ${ }^{3}$.

Pues bien, siguiendo esta distinción y modo de operar de la justicia como equidad, se puede perfectamente distinguir, a mi juicio, entre la tolerancia con relación a las cuestiones de justicia doméstica (y en parte local) o política interior, y la tolerancia en el ámbito de la justicia global, es decir, con relación a la política exterior de una sociedad liberal abierta a otras sociedades tanto liberales como no liberales. Así, según mi interpretación, al considerar este segundo momento

\footnotetext{
${ }^{1}$ Rawls, John: Justice as Fairness. A Restatement [2001], p. 11 (trad. cast., p. 35). En adelante siempre citaré las obras de Rawls indicando entre paréntesis la página de la traducción, y entre corchetes el año de la publicación original en inglés.

${ }^{2}$ Rawls, John: Justice as Fairnes. A Restatement, 2001, p. 10 (p. 33).

3 Ibíd., pp. 11-12 (p. 35).
} 
hacia fuera de la justicia obtenemos una visión completa de lo que en el pensamiento de Rawls vendría a representar una teoría liberal de la tolerancia.

La necesidad de la tolerancia en la sociedad doméstica es planteada ante el hecho del pluralismo, esto es, ante la existencia de una diversidad de doctrinas religiosas, filosóficas y morales encontradas e irreconciliables entre sí, que son el resultado del ejercicio de la razón humana en contextos institucionales libres. Como tal, éste es un rasgo permanente de las sociedades abiertas que, debido a la imposibilidad de un entendimiento común y permanente en torno a una de tales doctrinas - a no ser mediante el uso opresivo del poder del Estado-, plantea el desafío de encontrar una concepción pública de la justicia que pueda ser aceptada por esas mismas doctrinas enfrentadas. Con esta finalidad, según mi interpretación, Rawls se sirve de la tolerancia en dos momentos: el primero, o ex ante, se ubica en el ámbito de la construcción hipotética de la llamada "posición original” y las condiciones de imparcialidad en que las partes deciden sobre los principios públicos de la justicia. Aquí se trata de la tolerancia de las concepciones morales comprehensivas que se expresa bajo la idea del "velo de la ignorancia" que, como se sabe, opera imponiendo un conjunto de restricciones a la información que las partes poseen de sí mismas. Así, cuando la cuestión trata, por ejemplo, sobre qué principio deben adoptar las partes para regular las libertades ciudadanas con relación a sus intereses fundamentales religiosos, filosóficos y morales, ellas ignoran precisamente cuáles son en concreto esas doctrinas comprehensivas. De este modo las partes arriban al primer principio de la justicia como equidad ${ }^{4}$. En cambio, el segundo momento, o ex post, se plantea para hacer frente a los problemas que afectan a una sociedad bien ordenada cuya estructura básica está regida por la concepción pública de la justicia obtenida en el momento anterior. A diferencia del primer momento, Rawls habla aquí de la tolerancia como una virtud política característica de los

${ }^{4}$ La justicia como equidad se define en la concepción de Rawls a través de dos principios fundamentales que en A Theory of Justice [1971] son formulados de la manera siguiente: "Primer Principio: cada persona ha de tener un igual derecho al más amplio sistema total de libertades básicas iguales compatible con un sistema similar de libertad para todos”, Rawls, John: A Theory of Justice [1971], 1999, p. 266 (pp. 340-341). Una versión corregida de este principio aparece en Rawls, John, “The Basic Liberties and Their Priority”, 1982, p. 5, y también en Political Liberalism [1993], 1996, pp. 5-6 (p. 35). 
ciudadanos democráticos cuando hacen uso de la "razón pública" ( $p u$ blic reason $)^{5}$ en sus debates sobre cuestiones que afectan a las esencias constitucionales y la justicia básica. En este sentido, una sociedad bien ordenada promueve el bien de sus miembros a través de un punto de vista moral independiente, esto es, que no depende de ninguna doctrina moral, religiosa o filosófica particular. Esto trae como consecuencia que cualquier demanda sobre la estructura básica debe estar fundada en los principios públicos de justicia que todos han aceptado en las condiciones hipotéticas de la posición original. De este modo, los ciudadanos se sirven de la razón pública para justificar sus puntos de vista en el foro público político siguiendo el principio de tolerancia no como un simple modus vivendi (es decir, como un equilibrio de fuerzas políticas), sino que en virtud de lo que Rawls denomina un consenso superpuesto (overlapping consensus) que apoya una razonable concepción política de la justicia que se expresa en términos de los derechos y deberes que protegen la libertad religiosa, filosófica y moral de todos los ciudadanos ${ }^{6}$.

En general, se puede sostener que en ambos momentos (ex ante y ex post) la tolerancia opera en la sociedad doméstica como un "método de evitación" (method of avoidance) que pone entre paréntesis o deja aparte las doctrinas comprehensivas religiosas, filosóficas y mora-

${ }^{5}$ La razón pública forma parte de la concepción política de la justicia y representa la razón de ciudadanos democráticos, siendo pública de tres maneras diferentes: 1) en cuanto razón de los ciudadanos, es la razón del público y, en este sentido, es la característica de un pueblo democrático; 2) en cuanto a su objeto propio, es el bien público, es decir, aquellas cuestiones de justicia fundamental que se refieren a la estructura básica de la sociedad; y 3) por último, en cuanto a su naturaleza y contenido, se vincula con los ideales y principios de la concepción de la justicia política que tiene una sociedad democrática; véase Rawls, John, Political Liberalism, 1996, p. 213 (pp. 247-248). Véanse los estudios de Godoy Arcaya, Óscar: "Democracia y Razón Pública. En Torno a John Rawls”, 2001; Correa Casanova, Mauricio: "Dos Versiones Rivales sobre la Tolerancia. La Crítica de Michael Sandel a John Rawls”, 2006, y “La Tolerancia en el Uso de la Razón Pública”, 2007.

${ }^{6}$ En general, el consenso superpuesto (o entrecruzado) se refiere a un tipo de acuerdo entre las diferentes doctrinas comprehensivas razonables (no irrazonables o irracionales), por el cual ellas adhieren a la concepción política de la justicia desde su propio punto de vista. Este acuerdo posibilita la unidad social en torno a la concepción política, que ha sido presentada de un modo independiente de las doctrinas comprehensivas, religiosas y no religiosas; como también la estabilidad, en la medida en que los intereses esenciales de los ciudadanos políticamente activos y sus doctrinas razonables no entran en un conflicto excesivo con las exigencias de la justicia; véase Rawls, John: Political Liberalism, 1996, p. 134 (pp. 165-166). Un estudio crítico en Peña González, Carlos: "La Tesis del ‘Consenso Superpuesto’ y el Debate Liberal-Comunitario”, 2001. 
les en permanente disputa. Esto expresa que las verdades filosóficas, religiosas y morales no son necesarias para la obtención de una concepción pública de la justicia. Aun más, que dichas doctrinas comprehensivas resultan ser un obstáculo para la justificación moral de carácter público dadas las condiciones del pluralismo en una sociedad democrática. A juicio de Rawls, este modo de proceder forma parte esencial de la tarea de la filosofía política, la cual debe conducir nuestros más profundos conflictos políticos a un alto grado de abstracción a través de una especie de "abstinencia epistémica”7. Así, los problemas de la filosofía política han de ser tratados como problemas prácticos que requieren una justificación razonable, no como asuntos epistemológicos ni metafísicos ${ }^{8}$.

Ahora bien, dada la relevancia de la tolerancia en la construcción del punto de vista público de la justicia en una sociedad doméstica liberal, en las páginas siguientes quisiera ofrecer un desarrollo sistemático sobre la tolerancia como parte de la política exterior de una sociedad liberal abierta y en relación con otras sociedades tanto liberales como no liberales. Con este fin, comenzaré con una contextualización del tema de la tolerancia en el derecho de gentes (1), luego expongo y analizo cuatro cuestiones fundamentales, a saber, el significado y la necesidad de la tolerancia como parte de la política exterior de los pueblos liberales en la teoría ideal (2), la cuestión de los límites de la tolerancia de los pueblos bien ordenados, liberales y decentes (3), el

\footnotetext{
${ }^{7}$ Véase Raz, Joseph: "Facing Diversity, the Case for Epistemic Abstinence”, 1990.

${ }^{8}$ La síntesis que acabo de ofrecer sobre la tolerancia en la sociedad doméstica explicita claramente su papel decisivo para evadir las doctrinas comprehensivas con la finalidad de obtener una concepción pública de la justicia. Sorprendentemente, sin embargo, este aspecto no es mencionado por Rawls en la visión que él mismo nos entrega sobre su concepción de la tolerancia, cuyos puntos centrales serían los siguientes: “1) Las personas razonables no profesan todas la misma doctrina comprehensiva. Esto es consecuencia de las cargas del juicio; 2) De las muchas doctrinas comprehensivas razonables que se profesan, no todas pueden ser verdaderas o correctas desde el punto de vista de una doctrina comprehensiva; 3) No es irrazonable profesar cualquiera de las doctrinas comprehensivas; 4) Quienes profesan doctrinas razonables distintas de la nuestra son también razonables; 5) Al ir más allá del reconocimiento de la razonabilidad de una doctrina y afirmar nuestra fe en ella, no somos irrazonables; 6) Las personas razonables consideran irrazonable emplear el poder político, si es que lo poseen, para reprimir otras doctrinas razonables pero diferentes de la suya”, Rawls, John: The Law of Peoples, 1999, p. 6n (p. 28n).
} 
modelo de tolerancia religiosa de un pueblo jerárquico decente idealizado bajo el nombre de "Kazanistán" (4), y, para terminar, se examina el pretendido uso analógico de la tolerancia entre la sociedad doméstica y la sociedad de los pueblos (5).

\section{Derecho de gentes, tolerancia y utopía realista}

Con ocasión de la Oxford Amnesty Lecture de 1993, dedicada al estudio de los derechos humanos, Rawls se propuso desarrollar de forma más extensa y acabada el contenido del derecho de gentes o de los pueblos, y no así el de las naciones (law of nations) como lo había hecho antes en Theory of Justice [1971]. Así, mientras en Theory la tolerancia no aparece conectada al derecho internacional, en esta nueva formulación (Oxford Amnesty Lecture, 1993 ${ }^{9}$ ) podemos decir que representa explícitamente una de las ideas fundamentales de la relación entre los pueblos. En efecto, en la construcción del derecho de gentes liberal Rawls se plantea la pregunta sobre la tolerancia hacia otras formas de sociedades liberales y no liberales, así como por sus límites ${ }^{10}$. No obstante, unos años más tarde Rawls vuelve sobre esta conferencia de 1993, oportunidad en que corrige y aumenta la primera versión del derecho de gentes, la cual da lugar a una segunda versión que apareció en $1999^{11}$. Dado que Rawls mantiene en ambas versiones

${ }^{9}$ La Oxford Amnesty Lecture, 1993, fue publicada en la compilación de Schute, S. y Hurley, S.: On Human Rigths, 1993, y reproducida con posterioridad en la edición preparada por Freeman, Samuel (Rawls, John: Collected Papers, 2001, pp. 529-564). Entre los estudios críticos de esta primera versión podemos mencionar los trabajos de Pogge, Thomas: “An Egalitarian Law of Peoples”, 1994; Tesón, Francisco: "The Rawlsian Theory of International Justice”, 1995; Espósito, Carlos y Peñas, Francisco: “La Justicia como Equidad y el Derecho de los Pueblos”, 1995; Rubio Carracedo, José: “¿Derechos Humanos o Derechos Liberales?”, 1998, y “Justicia Internacional y Derechos Humanos”, 2000, entre muchos otros.

${ }^{10} \mathrm{Al}$ respecto, pueden verse los estudios críticos de Follesdal, Andreas: "The Standing of Iliberal States: Stability and Toleration in John Rawls' 'Law of Peoples”, 1997, y Tan, Kok-Chor: "Liberal Toleration in Rawls's Law of Peoples”, 1998, dedicados a la tolerancia en la primera versión del derecho de gentes.

${ }^{11}$ Rawls, John: The Law of Peoples and The Idea of Public Reason Revisited, 1999. (En adelante se citará de manera abreviada como The Law of Peoples.) Entre los cambios e innovaciones relevantes en la construcción del modelo que toma el derecho de gentes en esta última versión del derecho de gentes, se destaca la transición desde la noción de "Estado-nación” a "pueblo”; la concepción de una "utopía realista”; 
(de 1993 y 1999) sus ideas centrales sobre la tolerancia, para los efectos de nuestra exposición y examen vamos a seguir esta última versión (The Law of Peoples and The Idea of Public Reason Revisited, 1999) por considerar que es la definitiva.

Ahora bien, por derecho de gentes Rawls entiende "una concepción política particular del derecho (right) y la justicia que se aplica a los principios y las normas de la ley (law) internacional y su práctica" ${ }^{2}$. En este sentido, se trata de un núcleo normativo de principios políticos concretos que regulan las relaciones políticas entre los pueblos a partir de una idea liberal de justicia que es similar, aunque más amplia, al de la justicia como equidad expuesta en Theory [1971] ${ }^{13}$. El objetivo consiste en pasar del ámbito doméstico de la justicia como equidad en las sociedades liberales, hacia el ámbito internacional de las relaciones entre los pueblos. Así, la idea general del contrato social en la sociedad doméstica — como un mecanismo mediante el cual se expresa la voluntad libre de los individuos en la construcción de un concepto de justicia - se extiende a una Sociedad de los Pueblos. Esto se realiza en dos partes: en la primera se desarrolla lo que Rawls llama la "teoría ideal”, la cual se subdivide, a su vez, en dos etapas: 1) extensión de la idea general del contrato social a la sociedad de los pueblos democráticos liberales; y 2) extensión de la misma idea a la sociedad de los pueblos no liberales decentes. La segunda parte, llamada "teoría no ideal”, se ocupa de dos clases de asuntos: por un lado, de las condicio-

la idealización de un pueblo no liberal que denomina como "Kazanistán”; y la idea del "principio de asistencia”, entre otros aspectos importantes. Sobre esta última y definitiva versión se pueden ver entre muchos otros los estudios de Beitz, Charles: "Rawls's Law of Peoples”, 2000; Buchanan, Allen: "Rawls's Law of Peoples: Rules for a Vanished Westphalian World”, 2000, y Pogge, Thomas: "Rawls on International Justice”, 2001. Una visión general en Godoy Arcaya, Óscar: "Últimas Publicaciones de John Rawls”, 2000.

12 Rawls, John: The Law of Peoples, 1999, p. 3 (p. 13). A partir de esta especie de definición habría que distinguir el "derecho de gentes" del "derecho internacional”, ya que este último se caracteriza por ser un ordenamiento legal ya existente o establecido. Como indico en el texto, la denominación derecho de gentes no es concebida como un derecho de los Estados-nación, sino de los pueblos.

${ }^{13}$ Recuérdese que la idea de Theory [1971] consistía en mostrar cómo la justicia como equidad podía extenderse al derecho internacional con el propósito específico de juzgar los objetivos y los límites de la guerra justa a raíz del problema de la objeción de conciencia. En The Law of Peoples [1999], en cambio, Rawls pretende abarcar un terreno más amplio que involucra muchas más cuestiones, entre las que se cuenta, por cierto, la aplicación del principio de tolerancia en las relaciones entre los pueblos. 
nes de inobservancia y, por otro lado, de las condiciones desfavorables $^{14}$.

Como veremos más adelante, en la "teoría ideal" la idea de tolerancia juega un papel central para la extensión del derecho de gentes a los pueblos no liberales decentes. En cierto modo, aunque la analogía pueda quedar corta, podríamos decir que la tolerancia cumple las veces de una "bisagra" que abre la puerta del derecho de gentes a los pueblos no liberales que, sin embargo, satisfacen ciertas condiciones mínimas de justicia interna. Esto último es necesario por cuanto no todos los pueblos poseen gobiernos liberales. En este sentido, Rawls distingue entre cinco tipos de sociedades domésticas: 1) los pueblos liberales razonables ${ }^{15}$; 2) los pueblos decentes (o "pueblos jerárquicos decentes”) ${ }^{16}$; 3) los Estados proscritos (outlaw states); 4) los Estados lastrados por condiciones desfavorables; y 5) los Estados con absolutismos benignos ${ }^{17}$.

Teniendo en cuenta esta notable diferencia en el modo como se organizan internamente los pueblos, Rawls usa la expresión Sociedad de los Pueblos (Society of Peoples) para referirse "a todos aquellos pueblos que siguen los ideales y principios del derecho de gentes en sus relaciones recíprocas" ${ }^{18}$. En la medida en que todos los pueblos decentes, liberales y no liberales, cumplen el razonable derecho de gentes, una Sociedad de los Pueblos es razonablemente justa.

Ahora bien, el derecho de gentes expresa ideales y principios de la política exterior de una sociedad liberal razonablemente justa que, fundado en la hipótesis del contrato social a escala mundial, hace previsible la posibilidad cierta de que tales ideales y principios también sean razonablemente aceptables desde el punto de vista de otros pueblos no liberales y decentes. Precisamente esta confianza en la posibili-

${ }^{14}$ Rawls, John: The Law of Peoples, 1999, pp. 4-5 (pp. 14-15). Para una crítica sobre la extensión y aplicación del contrato social a los pueblos, véase Kuper, Andrew: "Rawlsian Global Justice: Beyond The Law of Peoples to a Cosmopolitan Law of Persons”, 2000.

${ }^{15}$ Rawls caracteriza a los pueblos liberales según los tres rasgos siguientes: 1) tienen un régimen razonablemente justo de democracia constitucional; 2) unos ciudadanos unidos por "simpatías comunes"; y 3) una naturaleza moral; véase Rawls, John: The Law of Peoples, 1999, pp. 23-25 (pp. 35-37).

${ }^{16}$ Rawls considera conjuntamente a los pueblos liberales y a los pueblos decentes como "pueblos bien ordenados" (well-ordered peoples).

${ }^{17}$ Rawls, John: The Law of Peoples, 1999, pp. 4 y 63 (pp. 14 y 77).

${ }^{18}$ Ibíd., p. 3 (p. 13). 
dad cierta de un acuerdo con los pueblos no liberales y decentes en torno al derecho de gentes justifica y hace necesaria la tolerancia como parte esencial de la política exterior de una sociedad liberal ${ }^{19}$.

El punto de partida en el proceso de construcción del derecho de gentes es análogo al descrito en Theory [1971] y en Political Liberalism [1993] respecto a la obtención de unos principios de justicia para el orden doméstico de una sociedad liberal. Según Rawls, el primer paso de la "teoría ideal" consiste en emplear de nuevo la idea de la posición original que se había utilizado para el contrato en la sociedad doméstica, pero ahora en un segundo nivel, más amplio y elevado, con el fin de extender la concepción de la justicia liberal al derecho de gentes ${ }^{20}$. En este segundo nivel se reúnen los representantes de los pueblos liberales, racionales y razonables, en condiciones de igualdad y guiados por los intereses fundamentales que inspiran los principios liberales de justicia de las sociedades democráticas. Al igual que en el caso doméstico, las partes también están sometidas a un velo de ignorancia, por el que, por ejemplo, ignoran el tamaño del territorio, la cantidad de población, los recursos naturales disponibles, el nivel de su desarrollo económico o la fuerza relativa del pueblo que representan. De este modo, la segunda posición original queda configurada a través de cinco características: 1) las partes están razonable y justamente situadas en condiciones de igualdad y libertad; 2) los pueblos se presentan como colectividades racionales; 3) los representantes de los pueblos deliberan sobre el contenido del derecho de gentes; 4) sus deliberaciones discurren ajustándose a las restricciones impuestas por un velo de ignorancia y 5) la elección de los principios del derecho de gentes se basa en los intereses fundamentales de los pueblos, de acuerdo con una concepción liberal de la justicia, ya elegida en la primera posición original ${ }^{21}$.

A primera vista, una diferencia importante en relación con la posición original en el caso doméstico (Theory y Political Liberalism) consiste en que las partes en la segunda posición original no reciben un

${ }^{19}$ Ibíd., pp. 9-10 (p. 19).

${ }^{20}$ El proceso de esta segunda posición original se describe brevemente en el parágrafo 58 de Theory [1971]. En todo caso, debe quedar claro que para Rawls no se trata de una posición original a escala global que incluya a todos los pueblos, liberales y no liberales. Lo cierto es que en un primer momento está restringida sólo a las sociedades liberales bien ordenadas según los criterios de una apropiada concepción política de la justicia, del tipo que la justicia como equidad es un ejemplo.

${ }^{21}$ Rawls, John: The Law of Peoples, 1999, p. 33 (p. 46). 
repertorio de principios e ideales alternativos al momento de realizar su elección. Al respecto, recuérdese que en la primera posición original (en la sociedad doméstica) las partes representativas disponen de varias alternativas para realizar su elección: los principios liberales de la justicia como equidad (como en Theory), o las varias formulaciones liberales de los principios de la justicia (como en Political Liberalism), o las otras alternativas como el utilitarismo, el intuicionismo racional y el perfeccionismo.

En The Law of Peoples [1999], en cambio, las únicas divergencias entre las partes corresponden a las diferentes interpretaciones de los principios del derecho de gentes, las cuales son debatidas por los representantes de los pueblos liberales en la segunda posición original. En este sentido, las partes no tienen, como representantes de los pueblos liberales con regímenes constitucionales, una doctrina comprehensiva del bien y, por tanto, sus intereses fundamentales están determinados por una concepción política de la justicia y por los principios por los cuales adhieren a un razonable derecho de gentes ${ }^{22}$. Con todo, los principios contenidos en el derecho de gentes son principios de justicia bien conocidos que forman parte de la historia del derecho internacional y de su práctica entre pueblos libres y democráticos. En conjunto, representan para Rawls la "carta fundamental" (basic charter) del derecho de gentes.

De este modo, una vez establecidas las condiciones hipotéticas en las que se ubican los representantes de los pueblos liberales para efectos del contrato, los principios elegidos para un razonable derecho de gentes serían los siguientes:

1. Los pueblos son libres e independientes, y su libertad y su independencia deben ser respetadas por otros pueblos.

2. Los pueblos deben cumplir los tratados y convenios.

3. Los pueblos son iguales y deben ser parte en los acuerdos que los vinculan.

4. Los pueblos tienen un deber de no intervención.

5. Los pueblos tienen el derecho de autodefensa pero no el derecho de declarar la guerra por razones distintas de la autodefensa.

6. Los pueblos deben respetar los derechos humanos.

${ }^{22}$ Ibíd., p. 40 (p. 53). 
7. Los pueblos deben observar ciertas limitaciones específicas en la conducción de la guerra.

8. Los pueblos tienen el deber de asistir a otros pueblos que viven bajo condiciones desfavorables que les impiden tener un régimen político y social justo o decente ${ }^{23}$.

En comparación con los principios que los representantes de los Estados eligen en Theory, podemos reconocer que los principios 1 a 5 y 7 recapitulan el derecho de las naciones tal como ahí fueron presentados $^{24}$. De particular interés resulta la proscripción de la guerra a excepción de la legítima autodefensa (principio 5), aunque debe añadirse ahora que para Rawls la guerra también estaría justificada, en los casos extremos, en defensa de los derechos humanos ${ }^{25}$. El deber de honrar los derechos humanos (principio 6) y el de asistir a los pueblos en condiciones desfavorables (principio 8) son nuevos. El primero de estos dos nuevos principios es significativo, ya que pone límites a los poderes de la soberanía, y el segundo es un llamamiento para que sea posible en la práctica un sistema internacional de asistencia al desarrollo financiado por una transferencia desde los países ricos ${ }^{26}$. En síntesis, estas adiciones constituyen los cambios progresivos y más substantivos respecto a Theory [1971].

Ahora bien, al formular estos principios de un razonablemente justo derecho de gentes Rawls concibe su proyecto como una "utopía realista” (realistic utopia). Con esta denominación no sugiere que el ideal político propuesto por los principios del derecho de gentes sea irrealizable o imposible, un mero producto de la fantasía, sino, por el contrario, que es efectivamente posible extender en la práctica los límites tradicionales de la realidad política. De este modo, a juicio de Rawls, se puede sostener una fundada esperanza en el futuro de una razonablemente justa Sociedad de los Pueblos en la que una sociedad

${ }^{23}$ Ibíd., p. 37 (p. 50).

${ }^{24}$ En Theory [1971] esos principios aparecen en el parágrafo 58, y son los siguientes: 1) el principio de igualdad, 2) el principio de autodeterminación, o el derecho de una nación a solucionar sus propios asuntos sin la intervención de poderes extranjeros, 3) el derecho de autodefensa, 4) el derecho a formar alianzas defensivas, 5) el principio del respeto de los tratados, y 6) el principio que regula los medios que puede usar una nación para emprender la guerra.

${ }^{25}$ Véase Rawls, John: The Law of Peoples, 1999, pp. 93n-94n (p. 111n).

${ }^{26}$ Véase Martínez Navarro, Emilio: Ética para el Desarrollo de los Pueblos, 2000. 
liberal coexiste con pueblos decentes en un mismo mundo social razonablemente justo ${ }^{27}$. En este sentido, Rawls sostiene que la tolerancia forma parte esencial de la tarea de la filosofía política — de manera semejante al caso de la justicia en la sociedad doméstica liberal- al formar parte de las seis condiciones que deben cumplirse como para que una Sociedad de los Pueblos pueda ser considerada como utopía realista ${ }^{28}$. Así, la idea de la tolerancia que fue aplicada en la sociedad doméstica, según Rawls, vale también para las relaciones entre los pueblos en una Sociedad de los Pueblos razonablemente justa. Efectivamente, para Rawls la tolerancia se impone si los pueblos que son miembros de esa sociedad emplean en sus relaciones mutuas la razón pública, ya que esto posibilita una justificación compartida que se puede descubrir mediante la reflexión que se orienta por la reciprocidad ${ }^{29}$. Esto quiere decir que la Sociedad de los Pueblos, como utopía realista, implica que los representantes de los pueblos jerárquicos decentes, en una posición original adecuada, adoptarán también los mismos ocho principios contenidos en el derecho de gentes.

\section{La tolerancia en la política exterior liberal}

Ya he anunciado que la idea de la tolerancia juega un rol central en la teoría ideal respecto a la extensión del derecho de gentes. Como hemos visto, la segunda posición original de la que se derivan los ocho principios que expresan el contenido del derecho de gentes es el resultado del acuerdo entre los representantes de los pueblos liberales. La

${ }^{27}$ Ibíd., p. 11 (p. 23).

${ }^{28}$ Las otras cinco condiciones son las siguientes: 1 ) es realista en la misma forma que una sociedad doméstica liberal o decente, lo cual exige emplear por segunda vez la idea de la posición original con las partes como representantes de los pueblos; también es realista en la medida en que resulta funcional y se puede aplicar a los arreglos políticos y a las relaciones de cooperación entre los pueblos; 2) es utópica por cuanto emplea ideales, principios y conceptos políticos y morales para definir los arreglos políticos y sociales razonablemente justos; 3) todos los elementos esenciales de una concepción política de la justicia deben estar incluidos dentro de la categoría de lo político; 4) la lealtad al derecho de gentes no tiene la misma intensidad en todos los pueblos, pero siempre debería ser suficiente; 5) el derecho de gentes ofrece un contenido de razón pública para la Sociedad de los Pueblos que es idéntico a los principios de justicia en una sociedad democrática; véase Rawls, John: The Law of Peoples, 1999, pp. 17-19 (pp. 28-31).

${ }^{29}$ Sin embargo, como veremos más adelante, considero que este supuesto uso analógico de la tolerancia no es plenamente satisfactorio. 
cuestión consiste en saber si es posible que además apoyen el mismo contenido otros pueblos no liberales. Nos dice Rawls:

El segundo paso de la teoría ideal es más difícil: nos desafía a especificar un segundo tipo de sociedad - una decente, aunque no una sociedad liberal-, que sea reconocida como miembro de bona fidae de una Sociedad de los Pueblos políticamente razonable y en este sentido 'tolerada' ${ }^{30}$.

Rawls entiende que sería irrazonable exigir a todos los pueblos un gobierno liberal, pues entonces sería un sinsentido el principio liberal de tolerancia; aún más, cree que la insistencia en que los demás pueblos sean también liberales impediría que el liberalismo político exprese la debida tolerancia frente a otras formas razonables de ordenar la sociedad. Así, el argumento desarrollado por Rawls establece que la tolerancia es exigida como una característica interna de la teoría liberal de la justicia cuando se desea extender el derecho de gentes e incorporar a la Sociedad de los Pueblos a las sociedades no liberales pero decentes. En este sentido, Rawls emprende un camino análogo al ejercicio de la tolerancia en el ámbito doméstico de las sociedades liberales. En sus propias palabras:

Nosotros reconocemos que una sociedad liberal ha de respetar las doctrinas comprehensivas —religiosas, filosóficas y morales - de sus ciudadanos a condición de que estas doctrinas sean ejercidas en modos compatibles con una razonable concepción política de la justicia y su razón pública. De manera parecida, nosotros decimos que, a condición de que las instituciones básicas de una sociedad no liberal cumplan ciertas condiciones específicas de rectitud y justicia política y conduzcan a su pueblo a honrar un justo y razonable derecho para la Sociedad de los Pueblos, un pueblo liberal ha de tolerar y aceptar esas sociedades ${ }^{31}$.

Así, mientras en el caso doméstico una teoría liberal de la justicia puede ser vista como proporcionando una solución al problema de la tolerancia entre personas consideradas como ciudadanos libres e iguales con distintas doctrinas comprehensivas, la misma teoría liberal (aunque adelgazada) extendida al derecho de gentes proporciona las

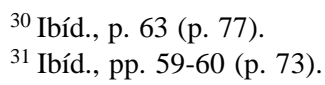


bases para la tolerancia hacia los pueblos no liberales. En otras palabras, así como en una sociedad liberal se deben tolerar las doctrinas comprehensivas razonables religiosas, filosóficas y morales sostenidas por los ciudadanos en virtud del punto de vista de una razonable concepción política de la justicia y su idea de razón pública, del mismo modo una sociedad liberal debe tolerar a las demás sociedades no liberales organizadas en base a doctrinas comprehensivas razonables, de forma políticamente decente.

Rawls utiliza el término "decente” para describir aquellas sociedades no liberales "cuyas instituciones básicas cumplen ciertas condiciones específicas de equidad y justicia política (incluido el derecho de los ciudadanos a tener un papel sustancial, a través de grupos y asociaciones, en la adopción de decisiones políticas) y conducen a sus ciudadanos a cumplir un derecho razonablemente justo de la Sociedad de los Pueblos"32. En este sentido, Rawls entiende la decencia como "una idea normativa de la misma clase que la razonabilidad [expuesta en Political Liberalism], si bien más débil o menos ambiciosa"33.

De este modo, según los criterios de decencia exigibles a un pueblo no liberal, los demás pueblos liberales deben determinar si debe ser tolerado y aceptado como miembro de la Sociedad de los Pueblos. Pero ¿cuáles son esas condiciones de decencia que una sociedad no liberal debe cumplir para ser tolerada y, en consecuencia, aceptada como miembro de bona fide de una razonable Sociedad de los Pueblos?

En concreto, Rawls describe dos criterios que especifican tales condiciones: el primero consiste en que la sociedad no liberal sea pacífica, es decir, que se esfuerce por alcanzar sus propios fines y metas legítimas a través de la diplomacia, el comercio y otros medios pacíficos; el segundo criterio se divide en tres partes y requiere que su sistema jurídico: a) garantice a todos los miembros del pueblo el respeto debido de sus derechos humanos; b) imponga obligaciones morales de buena fe a todas las personas residentes en su territorio; y c) por último, que sus jueces y administradores crean sincera y razonablemente que el derecho está efectivamente orientado por una idea de la justicia como bien común ${ }^{34}$.

\footnotetext{
${ }^{32}$ Ibíd., p. 3n (p. 14n).

${ }^{33}$ Ibíd., p. 67 (p. 81).

${ }^{34}$ Ibíd., pp. 64-67 (pp. 78-80).
} 
Así entendida, la concepción de decencia de los pueblos no liberales, según Rawls, representa "una idea mínima” que, si bien es distante de las concepciones liberales, al encarnarse en una sociedad no liberal "hace dignas de tolerancia a sus instituciones"35. Para Rawls estas condiciones no convierten en liberales a dichos pueblos, sino que sólo indican que son pueblos bien ordenados y decentes muy próximos a los pueblos liberales. Así pues, un pueblo que tiene una estructura básica decente ha de presentar las siguientes características: en primer lugar, tiene lo que Rawls llama una "jerarquía consultiva decente" (decent consultation hierarchy), por lo que recibe el nombre de "pueblo jerárquico decente" (decent hierarchical peoples) ${ }^{36}$. En este sentido, una jerarquía consultiva decente supone que "la estructura básica de la sociedad debe incluir una familia de cuerpos representativos cuya función en la jerarquía es participar en un procedimiento establecido de consulta y preservar lo que la concepción popular de la justicia como bien común considera que son los intereses más importantes de todos los miembros del pueblo"37. En segundo lugar, son pueblos confesionales, esto es, su estructura básica está influenciada por una determinada doctrina comprehensiva religiosa o secular, pero que es pacífica y no expansionista $^{38}$. En tercer lugar, es un pueblo cuyo sistema legal está

\footnotetext{
${ }^{35}$ Ibíd., p. 67 (p. 81).
}

${ }^{36}$ Ibíd., p. 63 (p. 77). Nos dice Rawls que tales pueblos son en general asociacionistas, lo cual quiere decir que en la vida pública cada grupo tiene sus propios representantes en el sistema jurídico, los que a su vez forman parte de un sector de la jerarquía consultiva decente (ibíd., p. 64 [p. 78]). En contrapartida, como sabemos, la sociedad doméstica liberal no adopta la forma asociacionista, ni la forma comunitaria (como una clase especial de asociación que está gobernada por una doctrina comprehensiva, religiosa o secular que determina los objetivos y propósitos finales de una sociedad). Más bien sus objetivos están constitucionalmente definidos, como los que aparecen en el preámbulo de una constitución —una justicia más perfecta, las garantías plenas de la libertad individual o la defensa común-, los cuales están contenidos en una concepción política de la justicia y en la idea de razón pública que va unida a ella (véase Rawls, John: Political Liberalism, 1996, I, § 7).

${ }^{37}$ Ibíd., p. 71 (p. 85). Rawls añade tres observaciones importantes: la primera justifica la presencia de grupos (y no de individuos) representativos dentro de la jerarquía consultiva decente; la segunda se refiere a la naturaleza de la tolerancia religiosa; y la tercera alude a la representación de grupos sometidos a presión y abusos, tales como las mujeres (ibíd., pp. 72-75 [pp. 86-89]). Más adelante me detendré con más detalle en el examen de la tolerancia religiosa en un pueblo jerárquico decente.

${ }^{38}$ Ibíd., p. 64 (pp. 78-79). Por cierto que Rawls no se refiere a tales pueblos como confesionales, sin embargo, creo que esta denominación coincide con el hecho opuesto de que "una sociedad liberal con un régimen constitucional no tiene, como 
orientado por una idea de la justicia como bien común (common good idea of justice). Como tal, esta idea forma parte esencial de un pueblo jerárquico decente, la cual se caracteriza por los tres rasgos siguientes: a) asigna derechos humanos a todos los miembros de un pueblo ${ }^{39}$; b) indica los intereses más importantes que la sociedad como un todo se esfuerza por alcanzar para todos los miembros del pueblo ${ }^{40}$; y c) es un marco básico que contiene los valores religiosos y filosóficos de un pueblo dentro del cual es permisible el disenso o la protesta pública en una jerarquía consultiva decente ${ }^{41}$. Finalmente, en cuarto lugar, y como consecuencia de lo anterior, es un pueblo que respeta los derechos humanos, los cuales quedan garantizados para todos sus miembros a través de su sistema jurídico y con independencia del grupo distintivo al que pertenezcan ${ }^{42}$.

Ahora bien, una vez descritas las condiciones de decencia, así como la estructura básica de un pueblo jerárquico decente, nos encontramos en condiciones para abordar la pregunta obvia sobre la tolerancia como una cuestión esencial de la política exterior liberal, esto es, ¿qué significa la tolerancia en la teoría ideal del derecho de gentes? $\mathrm{Al}$ respecto, podemos responder diciendo que en lo esencial es la

sociedad liberal, una concepción comprehensiva del bien. Sólo los ciudadanos y las asociaciones dentro de la sociedad civil en el caso doméstico tienen tales concepciones” (ibíd., p. 34 [p. 47]). Además, los mismos ejemplos propuestos por Rawls insisten en que los pueblos no liberales y decentes están guiados por una doctrina comprehensiva religiosa como el Islam, tal como Kazanistán. En este sentido, según Rawls, aunque la doctrina comprehensiva religiosa puede tener un alcance interno que abarque la totalidad de la estructura del Estado, sin embargo, no es expansionista como la de los principales Estados europeos durante las guerras de religión de los siglos XVI y XVII; o también como el cristianismo medieval que, en cuanto religión que perseguía la conversión de todos los hombres, no reconocía límites territoriales a su autoridad y ansiaba extenderse al mundo entero. (Sobre las características del cristianismo medieval, vid., Rawls, John: Political Liberalism, 1996, p. xxv [p. 19].)

${ }^{39}$ Ibíd., pp. 66 y 88 (pp. 80 y 103).

${ }^{40}$ Ibíd., p. 71 (p. 85). Al respecto, las sociedades bien ordenadas con concepciones liberales de la justicia política también tienen una concepción del bien común en este sentido, "es decir, el bien común de alcanzar la justicia política para todos los ciudadanos y de preservar la cultura libre que esa justicia hace posible” (ibíd., p. 71n [p. 85n]). Esta idea ya estaba presente en Theory, lugar en el que Rawls afirma: "Se supone que el gobierno aspira al bien común, esto es, a mantener las condiciones y alcanzar los objetivos que son del mismo modo ventajosos para todos [...]. El bien común creo que consiste en unas condiciones generales que están en un sentido igualmente apropiado para beneficio de todos” (Rawls, John: A Theory of Justice, 1993, pp. 205 y 217 [pp. 268 y 282]).

${ }^{41}$ Ibíd., p. 72 (p. 86).

${ }^{42}$ Ibíd., p. 65 (p. 79). 
disposición moral y política de los pueblos liberales hacia los pueblos no liberales y decentes. Lo cual significa fundamentalmente dos cosas: primero, significa abstenerse de imponer sanciones políticas, militares, económicas o diplomáticas a un pueblo no liberal para obligarlo a cambiar sus costumbres; $y$, segundo, significa reconocer a los pueblos no liberales como miembros iguales y de bona fide de la Sociedad de los Pueblos, con ciertos derechos y deberes, incluido el deber de civilidad, que exige justificar con razones sus acciones ante los otros pueblos, de una manera apropiada para la Sociedad de los Pueblos ${ }^{43}$.

Así, y dado que los pueblos jerárquicos decentes cumplen ciertas condiciones razonables de justicia política a los ojos de los pueblos liberales, la tolerancia en la teoría ideal implica lo siguiente: un principio general que expresa una abstención deliberada en lo que respecta a ejercer el poder coercitivo de los pueblos liberales sobre los no liberales decentes, del que se deriva, por consiguiente, a) un principio de no intervención coercitiva en los procesos internos de esos pueblos decentes con la finalidad de que cambien sus estructuras sociales y políticas; y b) un deseo de inclusión de dichos pueblos en el marco de una razonablemente justa Sociedad de los Pueblos.

Como es fácil advertir, Rawls conecta la tolerancia, por un lado, con la ausencia de sanciones o castigos para los pueblos no liberales; es decir, con la no intervención a través de medios coercitivos. Algunos podrían estimar que la tolerancia no es necesaria, pensando que el único camino adecuado consiste sencillamente en imponer sanciones a tales pueblos, ejercer coacción sobre ellos, de modo que a corto o mediano plazo se transformen en liberales ${ }^{44}$. Pero, como nos dice Rawls, "si los pueblos liberales exigen que todas las sociedades sean liberales y se impongan sanciones políticas a las que no lo son, entonces a los pueblos no liberales decentes, si es que los hay, se les negará el respeto debido”45. De ahí que la tolerancia posibilite la inclusión de los pueblos no liberales decentes en el procedimiento mismo de extensión de la segunda posición original, lo cual implica respetar a tales pueblos, sus tradiciones religiosas y culturales, así como las instituciones políticas que se derivan de ellas. El hecho de que no reciban sanciones por no ser liberales es parte esencial del debido respeto hacia esos pueblos.

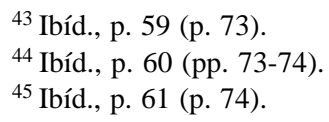


Así, una vez que quedan establecidas las condiciones para que un pueblo no liberal sea considerado decente, en las que se sustenta una política exterior tolerante, Rawls cree que podemos disponer de un razonable derecho de gentes que los pueblos no liberales decentes pueden aceptar en condiciones de igualdad. Esto es así porque precisamente tales condiciones de decencia se encuentran a medio camino entre los pueblos liberales y los pueblos no liberales proscritos; de otro modo, piensa Rawls, no sabríamos en base a qué principios podríamos establecer las sanciones o castigos adecuados para quienes se pongan fuera de la ley.

En definitiva, la tolerancia de los pueblos no liberales decentes posibilita el respeto, en condiciones de igualdad, que reclaman tales pueblos. Y esto a pesar de que su mundo social no sea del todo justo desde el punto de vista de los principios liberales. Por esta vía, Rawls cree que el hecho de que los pueblos decentes formen parte de una razonable Sociedad de los Pueblos permite que con el tiempo logren ser persuadidos de las ventajas de las instituciones liberales y se transformen por propia iniciativa. A través de una política exterior tolerante la “conversión liberal” se produce desde dentro de los pueblos no liberales. En efecto, como nos dice Rawls:

Los pueblos liberales deben tratar de estimular a los pueblos decentes y no frustrar su vitalidad con la agresiva pretensión de que todas las sociedades sean liberales. Más aún, si una democracia constitucional es superior a otras formas de sociedad, como creo que lo es, un pueblo liberal debe confiar en sus propias convicciones y suponer que una sociedad decente, cuando recibe el respeto debido de los pueblos liberales, puede reconocer las ventajas de las instituciones liberales y tratar de convertirse en liberal por iniciativa propia ${ }^{46}$.

${ }^{46}$ Ibíd., p. 62 (p. 75). En sentido estricto, Rawls no niega la pretensión de extender los principios políticos liberales a los pueblos no liberales decentes, más bien defiende un camino no coercitivo que espera una "conversión liberal" que, como tal, sea la expresión de un proceso interior, libre y voluntario, motivado por el testimonio de los pueblos liberales. Precisamente, con el recurso a la idea de tolerancia se niega una conversión que sea el resultado de la utilización de medios coercitivos que impongan los principios políticos liberales. Al respecto, compárese la asombrosa semejanza de este texto con la respuesta que Rawls ofrece en Theory al problema de la tolerancia hacia los intolerantes en la sociedad doméstica (véase Rawls, John: A Theory of Justice, 1993, pp. 192-193 [pp. 253-254]). A mi entender, en ambos casos se expresa la idea según la cual la estabilidad de las instituciones justas sirve para corregir las tendencias hacia la injusticia y 
En este sentido, a mi juicio, las condiciones mínimas estipuladas por Rawls para la tolerancia de los pueblos no liberales y decentes responden también a una estrategia de inclusión que en el fondo expresa un proyecto a largo plazo por el que es previsible lograr una implantación del modo de organización liberal en aquellos pueblos que aún dependen de doctrinas comprehensivas religiosas o filosóficas para diseñar sus instituciones.

\section{Los límites de la tolerancia y los derechos humanos}

Al tratar sobre los límites de la tolerancia, de particular interés es la condición política y moral del respeto a los derechos humanos. Precisamente ahora hemos de considerar este importante aspecto, ya que forma parte esencial de los límites de la tolerancia en la política exterior de los pueblos bien ordenados. Así, para comenzar, entre los derechos humanos que Rawls menciona estarían los siguientes: los derechos "a la vida (a los medios de subsistencia y a la seguridad); a la libertad (libres de la esclavitud, la servidumbre y el trabajo forzado, y provistos de una medida suficiente de libertad de conciencia y de libertad de religión y pensamiento); a la propiedad (propiedad personal); y a la igualdad formal expresada por las reglas de justicia natural (esto es, los casos similares son tratados similarmente)" ${ }^{47}$.

Aunque estos derechos pueden estar fundados en alguna concepción teológica, filosófica o moral que se deriva de una doctrina comprehensiva, religiosa o secular, lo cierto es que tales justificaciones doctrinarias no se aplican directamente al derecho de gentes. Como tal, lo que Rawls denomina derechos humanos "constituye una cierta porción de los derechos de los ciudadanos de una democracia constitucional o de los derechos de los miembros de una sociedad jerárquica decente"48.

En consecuencia, estos derechos han de ser aceptados por los diferentes pueblos a partir de su cultura característica y sus tradicio-

preservar la justicia de toda la organización, de modo que al ser tolerados, los intolerantes están capacitados por su sentido de la justicia para valorar las ventajas de vivir al amparo de una constitución justa; del mismo modo que los pueblos decentes, que son razonables, pueden ver las ventajas de los principios e instituciones liberales al convivir con ellos al amparo de una razonablemente justa Sociedad de los Pueblos.

${ }^{47}$ Rawls, John: The Law of Peoples, 1999, p. 65 (p. 79).

${ }^{48}$ Ibíd., p. 81 (p. 95). 
nes, razón por la cual no han de ser considerados como una imposición de los pueblos liberales o como patrimonio exclusivo de la tradición occidental. No son, por tanto, una imposición etnocéntrica. Por el contrario, los derechos humanos son universales, en el sentido de que "son intrínsecos al Derecho de Gentes y tienen un efecto político (moral) sin importar si son o no sostenidos localmente. Esto es, su fuerza política (moral) se extiende a todas las sociedades y son vinculantes para todos los pueblos y sociedades, incluidos los estados proscritos" $"$.

Los derechos humanos restringen las razones justificatorias válidas para la guerra y su conducción, así como también establecen los límites a la autonomía interna de los pueblos ${ }^{50}$. De ahí, por tanto, que el respeto de los derechos humanos desempeñe tres funciones relevantes: 1) su cumplimiento es condición necesaria (aunque no suficiente) para la decencia de las instituciones políticas y del orden legal de una sociedad; 2) su cumplimiento es suficiente para excluir la intervención justificada y enérgica en otros pueblos, por ejemplo, a través de sanciones diplomáticas y económicas, o en los casos graves por la fuerza militar; y 3) ellos fijan un límite al pluralismo entre los pueblos ${ }^{51}$. Podríamos decir que las funciones 1 y 2 expresan la condición y el sentido a favor de la tolerancia de los regímenes no liberales; en cambio, la función 3 pone límites a la tolerancia, en cuanto no todos los diferentes regímenes políticos son legítimos.

Así, una vez que los pueblos liberales y decentes sustentan conjuntamente los principios contenidos en el derecho de gentes, en virtud del cual han de regular de una forma razonablemente justa sus relaciones recíprocas, al mismo tiempo quedan establecidos para los pueblos bien ordenados los límites de la tolerancia. Como nos dice Rawls:

Tal como hemos formulado el Derecho de Gentes para los pueblos liberales y decentes, estos pueblos sencillamente no toleran a los estados proscritos. Esta negativa a tolerar estos estados es una consecuencia del liberalismo y de la decencia. Si la concepción política del liberalismo político es válida y si

${ }^{49}$ Ibíd., pp. 80-81 (p. 95).

${ }^{50}$ Ibíd., p. 79 (p. 93). Ambos aspectos, nos dice Rawls, reflejan cambios básicos e históricamente profundos en la concepción de los poderes de la soberanía concebida desde la Segunda Guerra Mundial.

${ }^{51}$ Ibíd., p. 80 (p. 94). 
los pasos que hemos dado para desarrollar el Derecho de Gentes son también válidos, entonces los pueblos liberales y decentes tienen el derecho, de acuerdo con el Derecho de Gentes, a no tolerar a los estados proscritos ${ }^{52}$.

Por consiguiente, los pueblos no liberales e indecentes, como podríamos llamar a los Estados proscritos, no han de ser admitidos como miembros de una Sociedad de los Pueblos, a la vez que se mantiene una predisposición amplia para intervenir en los casos más graves y extremos. Un Estado proscrito que viola los derechos humanos "ha de ser condenado y en casos graves puede ser objeto de enérgicas sanciones e incluso de intervención"53. De modo que los pueblos no liberales e indecentes quedan fuera de un razonable derecho de gentes y, por lo tanto, también fuera del alcance de la tolerancia.

Hasta aquí, al tratar sobre los límites de la tolerancia nos hemos movido dentro del ámbito de la teoría ideal del derecho de gentes; no obstante, como es fácil advertir, este aspecto tiene graves consecuencias en la teoría no ideal, sobre todo respecto a la cuestión del derecho a la guerra.

En términos generales, podríamos pensar que los pueblos no bien ordenados o proscritos son análogos a los intolerantes de la sociedad doméstica liberal, que niegan las condiciones equitativas acordadas en la posición original y en determinadas circunstancias representan una amenaza potencial para las libertades iguales de los demás. Esta analogía, en mi opinión, es bastante sugerente, ya que, al igual que en el caso doméstico, determina las razones, las circunstancias y los medios adecuados para tratar con aquellos pueblos que se ponen fuera de la ley y, por lo tanto, al margen de una razonable Sociedad de los Pueblos, cuyos miembros desean vivir en un mundo en el cual los demás aceptan y respetan el ideal del derecho de gentes.

Los pueblos bien ordenados, como hemos visto, son razonables; dicha razonabilidad les mueve a aceptar aquellos principios que especifican el derecho de gentes. Ellos no libran guerras entre sí, así como tampoco inician guerras para perseguir los intereses racionales del Estado, tales como el propio beneficio económico, el dominio de recursos naturales o el poder imperial. Una sociedad que persigue esos intereses no respeta el derecho de gentes y se convierte en un Estado proscri-

\footnotetext{
52 Ibíd., p. 81 (p. 95).

${ }^{53}$ Ibíd., p. 81 (p. 95).
} 
to ${ }^{54}$. En este sentido, el derecho de gentes admite el derecho a la guerra en aquellos casos en que ésta se encuentra justificada por cualquiera de los dos motivos siguientes: primero, cuando los Estados proscritos representan una amenaza para los pueblos liberales y decentes, la guerra está justificada en defensa propia, en cuyo caso los pueblos bien ordenados deben creer "sincera y razonablemente que su seguridad y estabilidad están en peligro debido a las políticas expansionistas de los estados proscritos"55; y segundo, cuando los Estados proscritos, aunque no sean agresivos ni alimenten planes expansionistas, sin embargo, en su interior violen gravemente los derechos humanos de sus propios miembros. En estos casos hay una causa prima facie para intervenir de un modo coercitivo, aunque siguiendo un procedimiento adecuado que ha de distinguir entre "civilizaciones avanzadas" (advanced civilizations) y "sociedades primitivas" (primitive societies) ${ }^{56}$. Entre ambas la diferencia estriba en que mientras las primeras buscan intercambios comerciales y otros arreglos cooperativos con las sociedades bien ordenadas, en cambio las segundas no reciben ninguna influencia efectiva de los pueblos liberales y decentes ${ }^{57}$.

${ }^{54} \mathrm{Al}$ respecto, creo que está suficientemente probada la posibilidad de que también existan los "estados liberales proscritos", o "estados canallas" (rogue state), como los denomina Noam Chomsky (Estados Canallas. El Imperio de la Fuerza en los Asuntos Mundiales, 2001), como lo fueron los Estados Unidos en los años 70 a raíz de su política exterior y su ideología de la Seguridad Nacional (hoy nuevamente resucitada después del 11-S y la amenaza del terrorismo islámico internacional). Podemos considerar estos regímenes como internamente bien ordenados, pero que en su política exterior se guían según sus propios intereses racionales y no se consideran obligados a actuar de acuerdo con las normas internacionales. Como nos dice Rawls, tales fueron los casos de los regímenes que siguieron al derrocamiento de Allende en Chile, de Arbenz en Guatemala, de Mossadegh en Irán y, se podría añadir, de los sandinistas en Nicaragua (Rawls, John: The Law of Peoples, 1999, p. 53 [p. 65]). Sin embargo, no deja de ser una sorpresa que para Rawls éstos y otros muchos ejemplos de la realidad política internacional sólo prueben que las sociedades liberales "pueden actuar incorrectamente" (ibíd., p. 91n [p. 109n]). Lo cierto es que uno hubiese esperado una atención mucho mayor y una crítica más profunda de la política intervencionista que ha caracterizado de forma permanente la política exterior de los Estados Unidos, la cual no deja de representar hasta nuestros días una seria amenaza para la soberanía y el desarrollo de muchos pueblos incluso democráticos.

${ }^{55}$ Rawls, John: The Law of Peoples, 1999, pp. $90-91$ (p. 108). Nos dice Rawls que esto incluye el derecho a ayudar a los aliados a defenderse.

${ }^{56}$ Ibíd., pp. 93n-94n (p. 111n).

${ }^{57}$ Hay que advertir que en el caso de las civilizaciones avanzadas Rawls defiende la hipótesis según la cual tales pueblos, por estar en contacto e influencia con la civilización y cultura liberal, pueden llegar a aceptar y a poner en práctica los principios políticos liberales, de modo que se produzca lo que he dado en llamar una "conversión liberal”. 
En todo caso, Rawls nos dice que un pueblo proscrito:

(...) no puede protestar por la condena de la sociedad mundial si sus instituciones domésticas violan los derechos humanos o limitan los derechos de las minorías que viven en ellos. El derecho de un pueblo a la independencia y a la autodeterminación no puede servir de escudo frente a aquella condena, ni siquiera ante la intervención coercitiva por otros pueblos en los casos graves ${ }^{58}$.

En este contexto, dado un razonablemente justo derecho de gentes, los pueblos bien ordenados tienen como objetivo principal a largo plazo conseguir que todos los pueblos respeten y cumplan tales derechos, de modo que se conviertan en miembros de bona fide de la Sociedad de los Pueblos. Tal objetivo supone establecer instituciones y prácticas comunes (v. gr. las Naciones Unidas) que sirvan como una especie de centro confederativo y foro público para expresar sus opiniones y políticas comunes, pudiendo realizar una crítica y denuncia permanente de las injusticias y crueldades llevadas a cabo por los Estados proscritos o fuera de la ley ${ }^{59}$.

\section{La tolerancia religiosa en Kazanistán}

Como hemos indicado, una de las condiciones que deben mantener los pueblos jerárquicos decentes se refiere a la tolerancia religiosa. Rawls sostiene que aunque en este tipo de sociedades decentes la política interior puede estar orientada por una religión oficial como autoridad suprema y controlar la política gubernamental en ciertas materias, no obstante, cuando se trata de la política exterior, esa autoridad no se extiende a las relaciones políticas con otras sociedades ${ }^{60}$.

Un pueblo no liberal propuesto por Rawls es el idealizado bajo el nombre de "Kazanistán”, un pueblo jerárquico e islámico que no establece la separación entre la Religión y el Estado, pero que es tolerante

${ }^{58}$ Rawls, John: The Law of Peoples, 1999, p. 38 (p. 51). La intervención coercitiva implica en primer lugar el recurso a sanciones (diplomáticas o económicas) en espera de que tales pueblos cambien su conducta criminal. Sólo en el caso en que a pesar de las sanciones se persista en la violación de los derechos humanos se podría proceder a una intervención militar.

${ }^{59}$ Ibíd., p. 93 (p. 110).

${ }^{60}$ Ibíd., p. 74 (pp. 87-88). 
con las religiones no oficiales que subsisten en su interior. La doctrina de la tolerancia religiosa que Rawls atribuye a los dirigentes de Kazanistán corresponde a la del Islam en el Imperio Otomano de hace varios siglos, donde se toleraba a judíos y cristianos.

Esta doctrina — en palabras de Rawls - afirma la honestidad de todas las religiones decentes y ofrece los elementos esenciales que exige una utopía realista. De acuerdo con esta doctrina: (a) todas las diferencias religiosas entre los pueblos son queridas por la divinidad, sin importar que los creyentes pertenezcan a la misma o a diferentes sociedades; (b) el castigo de las creencias erróneas corresponde sólo a Dios; (c) las comunidades de diferentes creencias deben respetarse entre sí; y (d) la fe en la religión natural es innata en todos los pueblos $^{61}$.

En este caso se entiende que la doctrina religiosa (el Islam) como religión oficial de un pueblo jerárquico decente no es del todo irrazonable, como tampoco es del todo razonable. Esto quiere decir que admite una medida suficiente de libertad de conciencia y de religión, aunque no sea tan amplia ni tan igual para todos sus miembros como en una sociedad liberal. También significa que ninguna religión es perseguida, como tampoco se les niega a los ciudadanos de otras confesiones las condiciones cívicas y sociales que les permitan que puedan realizar sus prácticas en paz y sin temor. Incluso, en virtud de la desigualdad, o quizás también por otras razones, en Kazanistán se permite el derecho de emigración. Como afirma Rawls:

El Islam es la religión preferida y sólo los musulmanes pueden ocupar los altos cargos de autoridad política e influir en las principales decisiones políticas del gobierno, incluida la política exterior. Y sin embargo se toleran otras religiones, que se pueden practicar sin temor o sin pérdida de los derechos civiles, con excepción del derecho a los altos cargos políticos o judiciales (...). Se estimula a las otras religiones y asociaciones a que tengan una floreciente vida cultural propia y tomen parte en la vasta cultura cívica de la sociedad ${ }^{62}$.

Pues bien, este tipo de tolerancia religiosa que caracteriza a la política interna de Kazanistán —y que Rawls parece aceptar de buen

\footnotetext{
${ }^{61}$ Ibíd., p. 76n (pp. 89n-90n).

62 Ibíd., pp. 75-76 (p. 89).
} 
grado dentro de las condiciones mínimas de decencia- resulta ser de particular interés en comparación con el tipo de tolerancia que es aceptado para la sociedad doméstica liberal. Por este motivo quisiera a continuación examinar brevemente la cuestión de la tolerancia religiosa con la finalidad de poner en cuestión la posibilidad de que un pueblo como Kazanistán pueda efectivamente arribar a los principios liberales que Rawls supone que en algún momento podrán alcanzar los pueblos jerárquicos decentes al ver sus incomparables ventajas. Como también cuestionar el hecho de que sus representantes puedan adherir al derecho de gentes, al menos según el modo que Rawls espera.

No deja de ser sorprendente que Rawls acepte (en términos de decencia) la tolerancia religiosa en Kazanistán, no sólo por la generalidad de su descripción, sino sobre todo porque el objeto de la tolerancia aquí ya no son, como en el caso de la sociedad liberal, los individuos con sus distintas doctrinas comprehensivas razonables. En Kazanistán, por el contrario, el objeto de la tolerancia religiosa se encuentra representado por los diferentes grupos o comunidades religiosas existentes dentro de una sociedad en la que hay una religión dominante que tolera a las restantes. En este sentido, llama la atención que Rawls no nos ofrezca explicación alguna, ni siquiera marginal, sobre este evidente cambio en el planteamiento de la tolerancia, sólo nos dice: "Muchos caminos pueden conducir a la tolerancia”63. Y luego nos remite a la obra de Walzer sobre el tema ${ }^{64}$.

¿Por qué creo que Rawls debería darnos una explicación? Fundamentalmente porque el tipo de tolerancia religiosa que él acepta como parte de los principios internos de Kazanistán —y que coincide históricamente con la tolerancia religiosa del Imperio Otomano, comúnmente conocida como el "sistema del mijo"65_, en la práctica no condujo al reconocimiento de los derechos individuales que son característicos de los principios políticos liberales. En este sentido, no basta con decir que la tolerancia se dice de muchas maneras, así como tampoco es suficiente la pura contemplación de las ventajas incomparables de vivir conforme a los principios políticos liberales para que un pueblo como Kazanistán pueda llegar a ser liberal. Una esperanza semejante debe

${ }^{63}$ Ibíd., p. 76n (p. 89n).

${ }^{64}$ Véase Walzer, Michael: On Toleration, 1997.

${ }^{65}$ Véase Braude, Benjamin y Lewis, Bernard, comps.: Christians and Jews in the Ottoman Empire. The Functioning of a Plural Society, Vol. I: The Central Lands, 1982. 
estar sustentada, al menos, en la suposición de que las condiciones de decencia reflejan la posibilidad cierta de que tal esperanza se vea cumplida. Si la tolerancia religiosa, como parte de una utopía realista, ha de ser una de las condiciones de decencia, esto bien puede justificar la tolerancia hacia tales pueblos, pero si además Rawls pretende justificar un proceso paulatino de liberalización o "conversión liberal” de esos mismos pueblos, esto parece poco plausible.

Si atendemos a la teoría de la justicia para la sociedad liberal, podemos observar que Rawls no considera explícitamente a las minorías culturales, como tampoco la cuestión de los derechos de grupo —étnicos o nacionales-; bien sabido es que su planteamiento es marcadamente individualista. En este sentido, la prioridad de la igualdad de la libertad representa una de las bases de la moralidad política para restringir la libertad de los grupos con pretensiones antiliberales. Para Rawls, el ordenamiento jurídico protege el derecho de todo individuo a realizar libremente y sin ninguna intervención coercitiva la propia libertad de elección de su plan racional de vida. Como él mismo nos advierte, los individuos "no se ven a sí mismos como inevitablemente atados a seguir una particular concepción del bien y de los fines últimos a los que en un momento dado adhieren", por eso son "capaces de revisar y de cambiar esta concepción”. Pueden "distanciarse” de sus fines actuales para "examinar y evaluar" el valor de los mismos ${ }^{66}$. Al respecto, si consideramos a las comunidades religiosas dentro de la sociedad liberal, es fácil ver que todos los individuos tienen la libertad no sólo de profesar y actuar según su propia fe, sino también de buscar nuevos adeptos (proselitismo), cuestionar la doctrina de su propia iglesia (herejía), renunciar completamente a su fe (apostasía) y convertirse a otra religión diferente o simplemente no profesar ninguna (ateísmo).

Lo dicho hasta aquí es el reflejo de la tolerancia liberal en virtud del punto de vista individualista para el caso doméstico. En este contexto, se puede comparar el modelo de tolerancia liberal basado en la libertad individual — que sería el desarrollado por Rawls— con el modelo basado en los derechos de grupo, según se encuentra expresado en el "sistema del mijo" practicado en el Imperio Otomano ${ }^{67}$. Este

${ }^{66}$ Rawls, John: Collected Papers, 2001, p. 544.

${ }^{67}$ Un intento semejante ha sido ampliamente desarrollado por Kymlicka, Will: Ciudadanía Multicultural, 1996, y “Two Models of Pluralism and Tolerance”, 1998. 
ejercicio es interesante en la medida en que Rawls remite de manera insistente a lo que debemos aprender de las lecciones de la tolerancia religiosa que se derivan de la Reforma en los siglos XVI y XVII, la cual culmina en el reconocimiento de la libertad individual. La pregunta ad hoc en este caso consiste en saber por qué Rawls no tiene en cuenta para el caso de la sociedad liberal otros modelos de tolerancia basados en los derechos de grupo. Y, una vez aclarado esto, en cambio, por qué en The Law of Peoples Rawls sí tiene presente el "sistema del mijo" como una condición aceptable para tolerar a los pueblos jerárquicos decentes.

$\mathrm{Al}$ respecto, parte de la respuesta de Rawls a la primera cuestión, según creo, se relaciona con las condiciones del procedimiento constructivista que define los términos equitativos que posibilitan el acuerdo en torno a los principios de la justicia que se deciden en la posición original, algo que dista mucho de las condiciones de desigualdad y dominación en que se plantea el "sistema del mijo" del Imperio Otomano. En efecto, en las actuales condiciones de los regímenes democráticos modernos es evidente que un modelo de tolerancia como el "sistema del mijo" es diametralmente contrario a la concepción que los ciudadanos de estas sociedades democráticas tienen sobre su propia personalidad moral, así como a la concepción de la sociedad como un sistema equitativo de cooperación entre personas libres e iguales; por lo que, en consecuencia, nadie estaría dispuesto a ver limitada su libertad por no coincidir en determinado momento con algunas o todas las creencias religiosas que antes profesaba con devoción, o ver limitados sus derechos civiles y políticos por pertenecer a una religión minoritaria. En este sentido el "sistema del mijo" no fue en términos estrictos un intento de los otomanos por construir un consenso acerca de las condiciones de posibilidad equitativas de una sociedad pluralista en la cual conviven creencias religiosas y visiones del mundo radicalmente diferentes; sólo expresó el deseo de una religión dominante de convivir con otras comunidades minoritarias sometidas sin poner en peligro la estabilidad de su propio imperio ${ }^{68}$. En la experiencia otomana, los musulmanes eran el poder dominante, y desde ese lugar de dominación concedían a las comunidades débiles (tales como los griegos ortodoxos, los armenios ortodoxos y los judíos) amplios derechos de autogobierno en cuestiones religiosas, o incluso judiciales, pero no

${ }^{68}$ Kymlicka, Will: “Two Models of Pluralism and Tolerance”, 1998, p. 84. 
reconocían ningún derecho semejante a poder participar e intervenir de forma activa en las cuestiones más amplias del gobierno central. Como afirma Kymlicka: "aunque eran libres de regular sus asuntos internos, sus relaciones con los gobernantes musulmanes estaban estrechamente reguladas" ${ }^{\prime \prime}$.

Dadas estas limitaciones, Rawls no considera tal orden impuesto como un caso de tolerancia religiosa que pueda prestar alguna ayuda (o lección) a las actuales condiciones de las sociedades modernas, pero no sólo porque no admite la libertad individual, sino sobre todo, como advierte Halbertal, porque ofrece "un marco de extrema asimetría de poder"70. A mi entender, el "sistema del mijo" puede reflejar un modelo de tolerancia aceptable en determinadas condiciones históricas, como de hecho ha funcionado en la práctica, pero que no responde a las exigencias de las condiciones equitativas que Rawls pretende ofrecer en el marco de un régimen democrático moderno. En este sentido, se pueden considerar como intolerables las exigencias de aquellas comunidades que no quieren que el Estado proteja los derechos individuales con el fin de que cada ciudadano pueda expresarse libremente, cuestionarse y revisar sus propias creencias religiosas. La lección del "sistema del mijo" es obvia: la tolerancia de un grupo dominante sobre otras comunidades subyugadas que violan los derechos individuales no puede ser la base de la legitimidad política en una democracia liberal, ya que no define un pacto de reconciliación entre las diversas religiones, convicciones morales y formas de culturas a las que los ciudadanos de una sociedad pluralista y democrática pertenecen ${ }^{71}$.

En contrapartida, la exigencia de igual libertad en un régimen constitucional establece condiciones de justicia más razonables para personas racionales que se consideran libres e iguales y con capacidad para ejercitar sus dos facultades morales (un sentido de la justicia y una concepción del bien). En este sentido, el Rawls de Theory nos dice en un pasaje importante que las asociaciones religiosas tienen plena libertad para determinar sus propios principios internos de organización, siempre y cuando no violen la libertad individual que posee todo individuo, según los principios liberales, para decidir si continúa o no con su filiación ${ }^{72}$. Es decir, una condición de la justicia es que al interior de las

\footnotetext{
${ }^{69}$ Ibíd., p. 83.

${ }^{70}$ Halbertal, M.: “Autonomy, Toleration, and Group Rigths”, 1998, p. 107.

${ }^{71}$ Rawls, John: A Theory of Justice, 1993, p. 194 (p. 255).

${ }^{72}$ Ibíd., p. 186 (p. 245).
} 
asociaciones se respete la libertad de cada individuo para revisar su propia concepción del bien en la que se sustenta su plan racional de vida. Rawls supone ampliamente que todos los individuos reconocen esta exigencia en la posición original, lo cual quiere decir que los grupos se adaptan a las exigencias de la justicia. El hecho de que se adapten supone, a su vez, que el sentido de la justicia de los individuos es permanente y efectivo, tal como aparece en la concepción de una sociedad bien ordenada. Por tanto, ¿es justo que al interior de las asociaciones se permita la violación de la libertad individual? En los términos de la justicia como equidad la respuesta de Rawls es negativa. Esto es así porque en un régimen liberal no se trata de tolerar a los grupos que reclaman su derecho a limitar la libertad individual de sus propios miembros; más bien la cuestión estriba en saber si eso es o no justo en los términos de los principios acordados previamente según las condiciones estipuladas en la posición original. Esto nos viene a decir, en el fondo, que en el ámbito de las comunidades religiosas es intolerable la violación de la libertad individual, ya que eso transgrede las exigencias de la justicia. En consecuencia, el "sistema del mijo" es claramente incompatible con la teoría de la justicia rawlsiana porque restringe las libertades básicas adscritas a cada persona moral ${ }^{73}$.

Ahora bien, una vez aclarada la posición rawlsiana para el caso de la sociedad liberal a partir de un único modelo de tolerancia religiosa derivado de las lecciones de la Reforma, la cuestión siguiente consiste en desvelar las consecuencias que se derivan del hecho que Rawls admita la política de tolerancia religiosa del Imperio Otomano para los pueblos jerárquicos decentes que, como hemos visto, es diametralmente opuesta a las exigencias liberales. Como he anticipado, creo que esto hace imposible que tales pueblos puedan arribar a los principios liberales basados en los derechos individuales. Aún más, también suscita serias dudas sobre la posibilidad de que sus representantes en la segunda posición original adhieran al contenido del derecho de gentes, al menos según las razones que Rawls espera.

${ }^{73}$ En este sentido, un modelo de tolerancia como el "sistema del mijo" puede ser visto, como sugiere Will Kymlicka ("Two Models of Pluralism and Tolerance”, 1998, p. 89), como una suerte de hypercommunitarianism, en cuanto asume que la filiación religiosa es tan profundamente constitutiva de la identidad de las personas que ha de estar protegida para que pueda desarrollarse con eficacia, lo cual se expresa mediante la prohibición del proselitismo y la apostasía. Con todo, no hay mayor interés en que la gente tenga la capacidad moral para revisar, examinar e incluso cambiar sus propias convicciones. 
La cuestión de fondo consiste en que Rawls plantea la libertad de conciencia en los pueblos jerárquicos decentes desde el punto de vista de las relaciones intergrupales, pero descuidando, a mi juicio, la suerte que corren los individuos al interior de la comunidad religiosa a la cual pertenecen. En efecto, nos dice Rawls:

(...) esta libertad de conciencia puede no ser tan extensiva ni tal igual para todos los miembros de la sociedad: por ejemplo, una religión puede predominar legalmente en la administración del estado, mientras que a otras religiones, aunque toleradas, puede negárseles el derecho a ocupar ciertas posiciones. Me refiero a este tipo de situación como permitiendo "la libertad de conciencia, aunque no una libertad igual’74.

Y más adelante, Rawls vuelve a insistir en esta idea, al sostener que

(...) las doctrinas (comprehensivas) religiosas o filosóficas de una sociedad jerárquica decente no deben ser del todo irrazonables. Esto quiere decir, entre otras cosas, que estas doctrinas deben admitir una medida suficiente de libertad de conciencia, de religión y de pensamiento, incluso si estas libertades no son tan amplias ni tan iguales para todos los miembros de la sociedad decente como lo son en las sociedades liberales ${ }^{75}$.

Lo importante para Rawls, por tanto, consiste en que "ninguna religión sea perseguida o que le sean negadas las condiciones cívicas y sociales que permitan su práctica en paz y sin temor"76. En estos términos, sin embargo, el dato histórico fundamental consiste en que si bien el "sistema del mijo" permitió la coexistencia pacífica de religiones radicalmente diferentes (la tolerancia intergrupal), esto sólo fue posible a costa de aceptar el derecho de las comunidades religiosas minoritarias para limitar los derechos de sus propios miembros, por ejemplo, castigando severamente la herejía y la apostasía que impiden, como es obvio, el ejercicio de la libertad de conciencia (la tolerancia intragrupal) ${ }^{77}$.

${ }^{74}$ Rawls, John: The Law of Peoples, 1999, p. 65n (p. 79n).

${ }^{75}$ Ibíd., p. 74 (p. 88).

${ }^{76}$ Ibíd.

${ }^{77}$ Esto significa, por supuesto, que dichas comunidades privaron a los individuos de su propio poder moral. Como sostiene Will Kymlicka ("Two Models of Pluralism and Tolerance", 1998, pp. 87-90), el "sistema del mijo" restringe la autonomía individual; esto es, limita la libertad y la capacidad de los individuos para juzgar el valor de las prácticas heredadas y, en consecuencia, de formar y revisar sus propias concepciones de lo bueno. 
En definitiva, y dadas las condiciones internas del "sistema del mijo" practicado en el Imperio Otomano, la esperanza (o utopía realista) abrigada por Rawls, esto es, la de una "conversión liberal" de los pueblos jerárquicos decentes, parece poco probable. Y lo es, a mi entender, porque internamente no cuentan con los recursos políticos que les permitan reconocer las ventajas de la libertad e igualdad democráticas. Este hecho, por otra parte, también pone en cuestión que los pueblos jerárquicos decentes puedan aceptar el contenido de un razonable derecho de gentes según las razones estipuladas por Rawls. No obstante, esta conclusión no niega que tales pueblos puedan adherir al derecho de gentes, más bien indica que esa esperanza sólo podría estar fundada en otro tipo de razones, por ejemplo, en un mero modus vivendi, algo bastante menor que las expectativas de Rawls.

\section{Sobre el uso analógico de la tolerancia}

Para terminar quisiera examinar la cuestión siguiente: ¿opera la tolerancia — tal como sostiene Rawls - en forma análoga en el derecho de gentes y en la sociedad doméstica liberal? Aquí argumentaré que hay una diferencia crucial en la forma en que opera en ambos casos, la que dice relación con las condiciones normativas diseñadas por Rawls en la construcción, por un lado, de una concepción política de la justicia y, por otro lado, del derecho de gentes. A mi juicio, esta diferencia se convierte en una de las causas principales del problema aún insuperable de las posibilidades de acuerdo entre pueblos liberales y no liberales en base a una concepción de la justicia liberal adelgazada.

$\mathrm{Al}$ respecto, es conveniente recordar que, como he afirmado al inicio de este estudio, en el caso doméstico la tolerancia actúa como un "método de evitación” que opera en dos niveles: en primer lugar, con el fin de hacer posible una concepción pública de la justicia a través de un procedimiento constructivo que se lleva a cabo en la posición original y que impone a las partes un velo de ignorancia que "evita” las doctrinas comprehensivas religiosas, filosóficas y morales que sostienen los ciudadanos; $y$, en segundo lugar, como una virtud política que los ciudadanos democráticos ponen en juego al momento de hacer uso de la razón pública en una sociedad bien ordenada que se rige mediante la concepción política de la justicia obtenida en el momento anterior. Así, los ciudadanos “evitan” la verdad global de su 
propia doctrina comprehensiva, religiosa o secular. Ahora, sin embargo, en la teoría ideal del derecho de gentes, Rawls nos dice que el principio liberal de la tolerancia se dirige desde las sociedades liberales hacia las sociedades no liberales por la mediación de unas condiciones de decencia que han de satisfacer tales pueblos no liberales.

A simple vista, este supuesto uso analógico de la tolerancia no funciona correctamente. En efecto, la tolerancia en el derecho de gentes no concuerda con las condiciones normativas del caso doméstico que ponen en situación de igualdad e imparcialidad a todas las partes. En cambio, en el contexto internacional la tolerancia responde a una disposición unilateral que expresa una especie de indulgencia de algunas de las partes hacia otras. De hecho, como hemos visto, las sociedades liberales en la segunda posición original, debido a que comparten en distintos niveles alguna forma de concepción política de la justicia, son las que ofrecen un idóneo derecho de gentes a las demás sociedades no liberales. Sin embargo, a mi entender, la tolerancia puede ser recíproca en el caso doméstico porque previamente (en la posición original) la misma tolerancia ha invalidado las expectativas público-políticas de las doctrinas comprehensivas sostenidas por los ciudadanos, con lo que resulta menos traumático adherir a la concepción política de la justicia que precisamente posibilita la tolerancia en el ejercicio de la razón pública. Pero esto no sucede en el derecho de gentes, donde es evidente que Rawls toma como punto de partida lo que a su juicio representa la mejor forma de organización política existente, esto es, la liberal.

En este sentido, podríamos decir que el desarrollo de la tolerancia en The Law of Peoples está lejos de la gran tesis contenida en Political Liberalism, según la cual la tarea de la filosofía política consiste en aplicar el principio de tolerancia a la filosofía misma. Al menos, éste fue el anuncio original y prodigioso del principio de tolerancia -implícito en Theory y explícito en los escritos rawlsianos posteriores a partir de 1982-, el cual daba una respuesta plena a la vocación del liberalismo político para completar el proyecto de tolerancia religiosa iniciado en los siglos XVI y XVII, y superar así el simple modus vivendi a través de la posibilidad de un consenso superpuesto (overlapping). Desde esta perspectiva, uno esperaría la misma aplicación del principio de tolerancia en la construcción de un derecho de gentes por el que se integre a la totalidad de los pueblos (liberales y no liberales), pero sin condiciones previas. 
En sentido estricto, sin embargo, podríamos decir que en la teoría rawlsiana efectivamente se aplica el principio de tolerancia cuando se extiende el derecho de gentes, y que su aplicación hace que se relajen las exigencias de justicia liberales. En efecto, al igual que en el caso doméstico, son evitadas las diferencias que existen entre las doctrinas comprehensivas que subyacen en cada pueblo, pero a diferencia de lo que ocurre en el ámbito doméstico, también son evitadas las diferencias clave en las concepciones políticas de la justicia. Como nos dice McCarthy, Rawls trata de atenuar la tensión entre pueblos liberales y decentes a través de un doble recurso: a) construyendo dentro de su concepción de las sociedades jerárquicas bien ordenadas elementos que cree que los liberales considerarían como los requisitos mínimos de la decencia política que ha de ser tolerada; y b) dejando caer de su propia concepción del derecho de gentes para sociedades liberales (el primer paso de su teoría ideal) elementos que cree que algunas sociedades jerárquicas considerarían objetables ${ }^{78}$. No obstante, este mecanismo de evitación es sólo parcial si lo comparamos con el caso doméstico y trae como consecuencia más bien un mínimo decente cuya acomodación llevada a cabo en el derecho de gentes se encuentra con las siguientes objeciones obvias: a) que los liberales no acepten (como de hecho no aceptan) ese punto de vista intermedio entre lo razonable (libertades iguales para todos) y lo irrazonable (negación de la libertad igual para todos); y b) que las sociedades decentes (no liberales) no acepten (como de hecho no aceptan) algunas de las justificaciones políticas fundamentales sobre las cuales descansan las sociedades liberales, como por ejemplo las características igualitarias de la justicia.

A mi juicio, en este aspecto Rawls no es plenamente consecuente en la aplicación del principio de tolerancia a su proyecto para alcanzar un razonable derecho de gentes. Aún más, muestra un evidente retroceso hacia un concepto pre-moderno de tolerancia según el cual el liberalismo se impone como el mejor modelo de organización política (ideal) a las demás sociedades existentes. De ahí que persista una serie de preguntas: ¿por qué Rawls no aplica el principio de tolerancia como punto de partida en la construcción del derecho de gentes con el fin de alcanzar unas condiciones normativas de igualdad entre los pueblos? ¿Por qué algunos pueblos (los no liberales decentes) deben ser tolera-

${ }^{78}$ McCarthy, Thomas: "Unidad en la Diferencia: Reflexiones sobre el Derecho Cosmopolita”, 1997, p. 47. 
dos en condiciones ideales? Si Rawls desea construir un razonable derecho de los pueblos, ¿por qué no evita las exigencias liberales? ¿Por qué extiende a través del recurso a la tolerancia las exigencias mínimas de un pueblo liberal? ¿Por qué no parte del hecho de que todos los pueblos formen parte de la segunda posición original tras un velo de ignorancia (esto es, aplicando el principio de la tolerancia como método de evitación a las distintas formas de ordenar la sociedad) en pro de un derecho razonable de los pueblos?

Lo cierto es que la distinción rawlsiana entre la concepción política de la justicia, por un lado, y las doctrinas comprehensivas, por el otro, que resulta ser tan persuasiva en Political Liberalism, no es coherente con su distinción entre pueblos liberales y pueblos no liberales decentes, pues la justificación completa de la segunda posición original abandona la vía imparcial para llegar a un entendimiento a partir de la aplicación del principio de tolerancia como "método de evitación”.

A este tenor, podríamos decir que la tolerancia en The Law of Peoples no es una precondición para que opere la evitación que se describe en Political Liberalism. O, por lo menos, que esa evitación no es tan profunda como en el caso doméstico. En efecto, la necesidad de la tolerancia hacia los pueblos decentes no expresa de forma tan estricta esa elusión de las diferentes doctrinas comprehensivas en pro de una concepción política de la justicia para la sociedad doméstica liberal, sino más bien se trata de una evitación bastante menos extensa que propone una versión mínima o adelgazada del propio punto de vista liberal que, en cierto modo, trata a los pueblos decentes como si fueran intolerantes dentro de la sociedad doméstica. Creo que apoya esta idea el hecho de que en ninguna parte Rawls relaciona la idea de la tolerancia con la cuestión de la estabilidad del derecho de gentes; esto es, con la posibilidad de un consenso superpuesto (overlapping) entre los pueblos, lo cual supondría completar y extender el proyecto de tolerancia a nivel de la Sociedad de los Pueblos, superando con ello el simple modus vivendi.

Desde esta perspectiva, Rawls pasa de la tolerancia del "nosotros" que caracteriza a Political Liberalism, a la tolerancia del "nosotros" hacia “ellos” en The Law of Peoples. La primera es una tolerancia mutua que posibilita el logro de una concepción política de la justicia al interior de la sociedad doméstica; en cambio, la segunda es una tolerancia unilateral, en la medida en que somos "nosotros", liberales, que por 
mediación de unas condiciones mínimas de decencia consideramos razonable aceptar a determinados pueblos, pues una vez satisfechas esas condiciones, ellos pueden aceptar el mismo derecho de los pueblos liberales.

Por otra parte, que los regímenes tiránicos y dictatoriales no deben ser tolerados es algo que parece indiscutible para la gran mayoría de los liberales; sin embargo, resulta menos indiscutible la tesis rawlsiana según la cual la tolerancia deba extenderse hacia los pueblos no liberales y decentes ${ }^{79}$. Claramente se observa que los pueblos liberales toleran y aceptan a los pueblos decentes como miembros de bona fide de la Sociedad de los Pueblos. Esto es así porque la decencia de tales pueblos les movería a aceptar los mismos principios del derecho de gentes al cual han arribado los pueblos liberales. Sin embargo, cabe hacerse la pregunta: ¿cómo pueden los pueblos no liberales decentes aceptar tal contenido si no comparten la misma política interna que las sociedades liberales? Como sostiene Rasmussen ${ }^{80}$, sería muy difícil dar una justificación política de la tolerancia porque no hay establecida una reciprocidad política y, por lo tanto, no hay una noción igualitaria de los derechos individuales.

Ciertamente que Rawls tiene en cuenta esta objeción ${ }^{81}$, sin embargo, creo que no puede superar el hecho de que la tolerancia entre los pueblos liberales descansa sobre la base de una misma cultura política, o por lo menos semejante, y que esa cercanía dista mucho de los pueblos no liberales y del proyecto de un derecho de gentes entendido como utopía realista que desde Rousseau y Kant se identifica con una conexión fundamental entre política y moralidad. En este sentido, ¿por qué son los derechos políticos una condición de legitimidad que compromete sólo a los pueblos liberales? ¿Acaso la tolerancia liberal no puede ser crítica con la intolerancia de un gobierno sobre sus propios miembros, o con lo que permite al interior de los grupos religiosos o culturales que subsisten en su interior?

Por último, si tenemos en cuenta el desarrollo de la tolerancia en Theory y Political Liberalism, es sorprendente que Rawls nos diga

\footnotetext{
${ }^{79}$ Ésta es la tesis que discute Tan, Kok-Chor en su interesante trabajo "Liberal Toleration in Rawls's Law of Peoples”, 1998.

${ }^{80}$ Rasmussen, David: "Beyond Liberalism: Toleration and the Global Society”, 2001.

${ }^{81}$ Véase Rawls, John: The Law of Peoples, 1999, p. 84 (p. 99).
} 
ahora que la tolerancia se dice de muchas maneras, pues, si esto es así, ¿por qué, entonces, la tolerancia en la sociedad doméstica liberal se desenvuelve sólo sobre la base de una visión normativa individualista (abiertamente liberal)? ¿Acaso los grupos o las comunidades religiosas, étnicas o culturales que no son liberales - y que, no obstante, viven en sociedades liberales - no tienen derecho a exigir sus reivindicaciones en virtud a una forma distinta de tolerancia a la versión puramente individualista? Lo que pretendo decir con esto es que, a mi entender, la concepción de la tolerancia rawlsiana propone una división demasiado artificial por la que se torna intolerante con los grupos minoritarios dentro de la misma sociedad liberal. Esto produce una contradicción insuperable por la que pretende hacer coincidir artificialmente dos modelos de tolerancia, los cuales se expresan del modo siguiente: para el caso doméstico, una tolerancia que reposa en una visión imparcial e individualista; en cambio, para el caso de la Sociedad de los Pueblos, otra tolerancia en base a una visión que podemos denominar como parcial y comunitaria ${ }^{82}$.

\section{REFERENCIAS}

Beitz, Charles R.: “Rawls’s Law of Peoples”. En Ethics, Vol. 110, № 4 (2000), 669-696.

Braude, Benjamin y Lewis, Bernard (comps.): Christians and Jews in the Ottoman Empire. The Functioning of a Plural Society, Vol. I: The Central Lands. Nueva York: Holmes y Meier, 1982.

Buchanan, Allen: "Rawls's Law of Peoples: Rules for a Vanished Westphalian World”. En Ethics, Vol. 110, № 4 (2000), 697-721.

Chomsky, Noam: Estados Canallas. El Imperio de la Fuerza en los Asuntos Mundiales. Barcelona: Paidós, 2001.

Correa Casanova, Mauricio: "La Tolerancia Liberal. John Rawls en Diálogo con sus Críticos”. Tesis doctoral, Valencia: Universitat de València, 2005.

-: "Dos Versiones Rivales sobre la Tolerancia. La Crítica de Michael Sandel a John Rawls”. En Veritas, Vol. I, No 14 (2006), 97-119.

——: "La Tolerancia Política en el Uso de la Razón Pública”. En A. Squella (ed.), Filosofía y Política en John Rawls. Valparaíso: EDEVAL, 2007.

Espósito, Carlos y Peñas, Francisco: "La Justicia como Equidad y el Derecho de los Pueblos”. En Revista de Estudios Políticos, № 87 (1995), 221-237.

Follesdal, Andreas: “The Standing of Illiberal States: Stability and Toleration in John Rawls' 'Law of Peoples'”. En Acta Analytica, Vol. 12, No 18 (1997), 149-160.

${ }^{82}$ Véase Follesdal, Andreas: "The Standing of Illiberal States: Stability and Toleration in John Rawls' 'Law of Peoples'”, 1997. 
Godoy, Óscar: “Últimas Publicaciones de John Rawls”. En Estudios Públicos, 79 (2000), 451-469.

-: “Democracia y Razón Pública. En Torno a John Rawls”. En Estudios Públicos 81 (2001).

Halbertal, M.: “Autonomy, Toleration, and Group Rights: A Response to Will Kymlicka”. En D. Heyd (ed.), Toleration: An Elusive Virtue. Princeton-NJ: Princeton University Press, 1998.

Kuper, Andrew: "Rawlsian Global Justice: Beyond The Law of Peoples to a Cosmopolitan Law of Persons”. En Political Theory, Vol. 28, No 5 (2000), 640-674.

Kymlicka, Will: Ciudadanía Multicultural. Barcelona: Paidós, 1996. : "Two Models of Pluralism and Tolerance". En D. Heyd (ed.), Toleration. An Elusive Virtue. Princeton-NJ: Princeton University Press, 1998.

: La Política Vernácula. Nacionalismo, Multiculturalismo y Ciudadanía. Barcelona: Paidós, 2003.

Martínez Navarro, Emilio: Ética para el Desarrollo de los Pueblos. Madrid: Trotta, 2000.

McCarthy, Thomas: "Unidad en la Diferencia: Reflexiones sobre el Derecho Cosmopolita”. En Isegoría, No 16 (1997), 37-60.

Peña González, Carlos: “La Tesis del ‘Consenso Superpuesto’ y el Debate LiberalComunitario”. En Estudios Públicos 82 (2001).

Pogge, Thomas: “An Egalitarian Law of Peoples”. En Philosophy and Public Affairs, Vol. 23, No 3 (1994), 195-224.

: "Rawls on International Justice". En The Philosophycal Quaterly, Vol. 51, No 203 (2001), 246-253.

Rasmussen, David: "Beyond Liberalism: Toleration and the Global Society. Reflections on The Law of Peoples”. En W. Rehg y J. Bohman, eds., Pluralism and the Pragmatic Turn. MIT Press, 2001.

Rawls, John: A Theory of Justice [1971]. Oxford: Oxford University Press, 1999, edición revisada. [Trad. cast. Teoría de la Justicia. Madrid: FCE, 1993.]

-: "The Basic Liberties and Their Priority”. En S. McCurrin (ed.), The Tanner Lectures On Human Values. Salt Lake City: University of Utah Press, 1982.

: Political Liberalism [1993]. New York: Columbia University Press, 1996, 2a ed. [Trad. cast. El Liberalismo Político. Barcelona: Crítica, 1996.]

-: The Law of Peoples and The Idea of Public Reason Revisited [1999]. Cambridge, Mass., y Londres: Harvard University Press, 1999. [Trad. cast., El Derecho de Gentes y Una Revisión de la Idea de Razón Pública. Barcelona: Paidós, 2001.]

-: Justice as Fairness. A Restatement. Cambridge, Mass., y Londres: Harvard University Press, 2001. [Trad. cast. La Justicia como Equidad: Una Reformulación. Barcelona: Paidós, 2002.]

: Collected Papers. Cambridge, Mass., y Londres: Harvard University Press, 2001.

Raz, Joseph: "Facing Diversity, the Case for Epistemic Abstinence”. En Philosophy and Public Affairs 19 (1990).

Rubio Carracedo, José: “¿Derechos Humanos o Derechos Liberales?”. En Doxa, No 21-II (1998), 421-436.

-: “Justicia Internacional y Derechos Humanos”. En J. Rubio Carracedo, J. M ${ }^{\mathrm{a}}$

Rosales y M. Toscano: Ciudadanía, Nacionalismo y Derechos Humanos. Madrid, Trotta, 2000. 
Sartori, Giovanni: La Sociedad Multiétnica. Pluralismo, Multiculturalismo y Extranjeros. Madrid: Taurus, 2001.

-: Extranjeros e Islámicos. Madrid: Taurus, 2002.

Schute, S. y Hurley, S.: On Human Rights. New York: Basic Books, 1993. [Trad. cast., De los Derechos Humanos. Madrid: Trotta, 1999.]

Tan, Kok-Chor: "Liberal Toleration in Rawls's Law of Peoples”. En Ethics, Vol. 108, № 2 (1998), 276-295.

Taylor, Charles: El Multiculturalismo y la Política del Reconocimiento. México: FCE, 1993.

Tesón, Francisco: “The Rawlsian Theory of International Justice”. En Ethics and International Affairs, Vol. 9 (1995), 79-99.

Walzer, Michael: On Toleration. New Haven and London: Yale University Press, 1997. 